\title{
O ensino do desenho de letras para engenheiros-arquitetos na Escola Politécnica de São Paulo: uma abordagem convencional
} The teaching of lettering design for architectural engineers in Escola Politécnica de São Paulo: a conventional approach

\author{
José Roberto D'Elboux
}

\author{
desenho de letras, letreiro arquitetônico, desenho arquitetônico, tipografia, normatização
}

Este artigo, descreve os resultados de uma investigação a respeito da existência de conteúdo programático abordando o ensino do desenho de letras, no curso para formação de engenheirosarquitetos da Escola Politécnica de São Paulo. O recorte temporal do estudo começa no ano de 1895, início do curso de engenheiro-arquiteto e estende-se até final da década de 1940. Nesse período, verificou-se que o conteúdo relativo ao desenho de letras era transmitido na disciplina "Desenho Topográfico e Cartográfico", compartilhada entre os cursos de engenheiro-civil, engenheiro-agrônomo e engenheiro-arquiteto. Os cursos de arquitetura, desde o século XIX, foram caracterizados pela influência do sistema de ensino das academias de belas artes, em que o desenho de letras estava associado à disciplinas de desenho linear. A presença desse conteúdo em desenho topográfico e cartográfico, encontra respaldo na proposta de um curso de arquitetura conduzido dentro de uma escola de engenharia e o consequente compartilhamento de disciplinas básicas entre as diferentes especialidades oferecidas. Como conclusão, temos que, assim como os símbolos e texturas utilizados em mapas e plantas topográficas, o ensino do desenho de letras foi relacionado a um contexto convencional, evidenciado pela observação de como diferentes estilos de letras eram associados a naturezas diferentes de informação existentes nos mapas e plantas, criando uma hierarquização dos níveis de informação textual.

lettering design, architectural lettering, architectural drawing, typography, standardization

This paper describes the results of an investigation about the existence of programmatic content addressing the teaching of lettering design within the undergraduate course of architectural-engineering at the Escola Politécnica de São Paulo. The study takes place from 1895, when the architectural-engineering course started until the end of the 1940's. During this period, the content related to lettering design was part of the discipline "Topographic and Cartographic Drawing", shared by civil-engineering, agronomicengineering and architectural-engineering undergraduate courses. Architecture courses since 19th century, were under the influence of the fine arts teaching method developed by the academies, in which lettering design was commonly associated with line drawing classes. The existence of this content in topographic and cartographic drawing, is supported by the proposal of an architecture course conducted within an engineering school, with the consequent sharing of basic disciplines among the different engineering specialties offered. Concluding, the teaching of lettering design was related to a conventional context, like the symbols and textures applied to maps and topographic plans. This is evidenced by observing how different styles of letters were associated with different kinds of information, creating hierarchic levels of textual information.

\section{Introdução}

Este artigo descreve os resultados de uma investigação a respeito da existência de conteúdo programático abordando o ensino do desenho de letras, dentro do curso de formação de engenheiros-arquitetos na Escola Politécnica de São Paulo, entre o ano de 1895, início do curso de engenheiro-arquiteto, até final da década de 1940. Sua motivação inicial foi a geração de subsídios para a tese de doutoramento "Letras e letreiros: manifestações do art déco em projetos arquitetônicos paulistanos (1928-1955)" defendida na Faculdade de Arquitetura e Urbanismo da Universidade de São Paulo, no ano de 2018, dentro do programa de PósGraduação em Design. A tese, em uma de suas questões secundárias, procura responder como se deu o ensino prático do desenho de letras no processo de formação dos profissionais

Anais do 9 CIDI e 9 CONGIC

Luciane Maria Fadel, Carla Spinillo, Anderson Horta, Cristina Portugal (orgs.)

Sociedade Brasileira de Design da Informação - SBDI

Belo Horizonte | Brasil | 2019

ISBN 978-85-212-1728-2
Proceedings of the 9th CIDI and 9th CONGIC

Luciane Maria Fadel, Carla Spinillo, Anderson Horta, Cristina Portugal (orgs.)

Sociedade Brasileira de Design da Informação - SBDI Belo Horizonte | Brazil | 2019

ISBN 978-85-212-1728-2 
que integraram os quadros dos escritórios de arquitetura da cidade de São Paulo durante a primeira metade do século XX.

Para tanto, além da revisão da bibliografia relacionada ao assunto, foi necessária uma ampla pesquisa em fontes primárias, no caso, a documentação disponível no Arquivo Histórico da Escola Politécnica da Universidade de São Paulo, na forma de atas, relatórios, programas de disciplinas, anotações de aula, apostilas e trabalhos de alunos, através dos quais foi possível confirmar a existência do ensino do desenho de letras no curso e conhecer o conteúdo envolvido em seu processo.

Para análise dos modelos ensinados, foi tomado como referência, um tratado sobre letreiramento em desenhos técnicos de autoria de Charles W. Reinhardt, editado nos Estados Unidos em 1897 e, quando aplicável, a consulta às normas técnicas em vigor.

\section{0 curso de engenheiro-arquiteto da Escola Politécnica de São Paulo}

A Escola Politécnica de São Paulo foi formada em 1893, proposta do então presidente da Câmara dos Deputados do Estado, Antonio Francisco de Paula Souza, como resposta à carência de mão de obra técnica, principalmente de engenheiros, incapaz de atender à demanda por desenvolvimento industrial e urbano gerada pelos resultados financeiros da produção e exportação de café (Santos, 1985, pp. 11-12).

Até esse momento, o ensino superior na cidade de São Paulo estava restrito ao curso de Direito da Academia do Largo São Francisco, o que obrigava os interessados em cursar engenharia, a optar pela Escola Politécnica do Rio de Janeiro ou pela Escola de Minas de Ouro Preto. Ou ainda, seguir rumo às escolas europeias.

A Escola Politécnica de São Paulo, começou a funcionar em 1894, tendo como diretor, o próprio Paula Souza e, como vice-diretor, Luiz de Anhaia Mello. Nesse primeiro momento, foram instituídos os cursos de Engenharia Civil, Engenharia Industrial, Engenharia Agrícola, e um curso anexo de artes mecânicas, voltado à formação de mão-de-obra técnica para alunos sem nível ginasial (Santos, 1985, p. 38).

Já no primeiro ano, a Congregação da Escola Politécnica de São Paulo promoveu uma reestruturação do curso, implantada a partir do ano seguinte, dividindo-o em duas etapas: Curso Fundamental ${ }^{1}$, onde estavam concentradas as disciplinas basilares, muitas delas compartilhadas entre as diferentes especialidades da engenharia, e Cursos Especiais Engenheiro-Civil, Engenheiro-Industrial, Engenheiro-Agrônomo e, agora também, EngenheiroArquiteto (Ficher, 2005, p. 26).

As disciplinas do curso, as denominadas "cadeiras", estavam distribuídas em diferentes seções. Cada "cadeira", ficava sob a responsabilidade de um "lente catedrático". Abaixo destes, estavam os "lentes substitutos", cuja função era repetir a matéria das cadeiras de uma seção. Haviam também as disciplinas chamadas de "aulas", de caráter prático, como Desenho Geométrico, Desenho Topográfico e Cartográfico, Elementos de Arquitetura e, Escrituração Mercantil, entre outras. Eram ministradas pelos chamados "professores de aula", docentes sem formação de nível superior ou cujos diplomas vinham de instituições não reconhecidas pela Escola Politécnica de São Paulo (Ficher, 2005, pp. 25-26).

De maneira geral, o curso da Escola Politécnica de São Paulo foi organizado como o do Polytechnikum de Karlsruhe, escola onde estudou Paula Souza, em que curso fundamental e os cursos especiais funcionavam na mesma instituição, diferente da Ecole Polytechnique de Paris, onde o curso fundamental tinha três anos de duração e era preparatório para ingresso em outras escolas de engenharia. Segundo Ficher, o curso de Engenheiro-Arquiteto, teve

\footnotetext{
1 O Curso Fundamental era compreendido por um ano de curso Preliminar e dois anos de curso Geral. Esse modelo funcionou até o ano de 1931, quando o Fundamental foi extinto, mantendo-se somente o Preliminar, que foi substituído em 1935 pelo Colégio Universitário, que era complementar ao ensino secundário (Ficher, 2005: 255-257). Situação mantida até 1947 quando da instalação da Faculdade de Arquitetura e Urbanismo. O curso de Engenheiro-Arquiteto da Politécnica foi oferecido pela última vez em 1948 (Santos, 1985: 259-260).
} 
como provável inspirador o arquiteto Ramos de Azevedo (Ficher, 2005, pp. 54-55).

Em situação diversa à existente no Rio de Janeiro ou Paris, onde a formação dos arquitetos estava vinculada às escolas de belas-artes, em São Paulo ${ }^{2}$ a arquitetura foi estudada como uma das especializações da engenharia, capacitando os alunos ao projeto e à construção (Ficher, 2005, p. 26).

\section{O ensino do desenho de letras na Escola Politécnica de São Paulo}

A menção ao desenho de letras na Escola Politécnica de São Paulo, aparece registrada pela primeira vez no Anuário Politécnico de 1900, como parte do programa da aula "Trabalhos Gráficos" do $1^{\circ}$ ano do curso de Engenheiro-Agrônomo para o período 1899-1900, sob a responsabilidade do professor Victor Dubugras ${ }^{3}$. No programa, o primeiro assunto a ser abordado era "Desenho Topográfico" e, como trabalho inicial, propunha a execução de uma prancha intitulada "Letras" (Escola Politécnica de São Paulo, 1900, p. 248-249). Um provável registro desse exercício, aparece na tese "Desenho Arquitetônico" do professor José Maria da Silva Neves (1943), reproduzida na Figura 1.

De influência moderna, inspirada no estilo Sezession, uma vertente do art nouveau originada em Viena, na Áustria, esse modelo de alfabeto foi de uso comum nos projetos elaborados por Victor Dubugras que, aparentemente, não teve dúvidas em transmitir uma opção pessoal de desenho de letras a seus alunos, mesmo tendo o ensino de desenho na Escola Politécnica recebido influência da escola clássica acadêmica por influência de seu ditretor, o arquiteto Ramos de Azevedo (Neves, 1943, p. 63-64).

No anuário de 1901, o programa da aula de "Desenho Topográfico" aparece assinado pelo professor Jorge Krichbaum ${ }^{4}$. Seu tópico inicial é intitulado "Preliminares. Letreiros e escalas" (Escola Politécnica de São Paulo, 1901: 204). Alguns anos depois, em 1912, o professor Krichbaum atualizaria o título desse tópico para "Preliminares: letras, letreiros e escalas". (Krichbaum, 1912). Também baseada em uma prancha sugerida por Krichbaum para ser copiada pelos alunos, apresenta ao contrário da de Dubugras, diversos estilos e modelos de letras diferentes (Fig. 2).

Houve uma pausa de vinte anos na publicação do Anuário Politécnico, que voltaria a circular somente em 1932. Nessa edição, o programa da disciplina Desenho Topográfico e Cartográfico, aparece agora sob responsabilidade do professor Francisco de Sales Vicente de Azevedo $^{5}$, que assumiu essa disciplina em 1921, com a morte do professor Krichbaum. Azevedo também manteve como primeiro tópico do curso "Preliminares: letras, letreiros e escalas" (Escola Politécnica de São Paulo, 1932, pp. 248-249) e, a prancha sugerida pelo professor para o exercício de cópia, é muito semelhante à utilizada por Krichbaum (Fig. 3).

Azevedo aposentou-se da Escola Politécnica no ano de 1946 e, assume a responsabilidade pelas aulas de "Desenho Topográfico e Cartográfico" o engenheiro John Settle Addison ${ }^{6}$,

\footnotetext{
${ }^{2}$ O curso de arquitetura da Escola de Engenharia do Mackenzie College, foi iniciado em 1917. Sua implementação, foi feita por Christiano Stockler das Neves a partir da estrutura do curso da Fine Arts School da Universidade da Pensilvânia, onde este havia estudado.

${ }^{3}$ Victor Dubugras, arquiteto nascido em 1868 em Sarthe na França, se mudou para São Paulo em 1891. Lecionou na Escola Politécnica de São Paulo entre 1894 e 1927, em diversas disciplinas que envolviam o desenho. Foi um dos arquitetos mais criativos do período, com incursões pelos estilos art nouveau e neocolonial. Seu projeto para a estação ferroviária de Mairinque, foi pioneiro no uso do concreto armado (Ficher, 2005: 75-83).

${ }^{4}$ Jorge Krichbaum nasceu em 1856 em Darmstadt, Alemanha, e formou-se engenheiro em 1879. Se muda para o Rio Grande do Sul em 1880 e, a partir de 1890, São Paulo. Entrou para o corpo docente da Escola Politécnica em 1895, onde permaneceu até 1921, ano de seu falecimento (Revista Politécnica,1922: 497-498).

${ }^{5}$ Francisco de Sales Vicente de Azevedo nasceu em São Paulo em 1890. Diplomado engenheiro-civil pela Escola Politécnica de São Paulo em 1914, assumiu a disciplina de Desenho Topográfico e Cartográfico em 1921, permanecendo nela até sua aposentadoria em 1946 (D'Alessandro, 1943-44: 133; Escola Politécnica, 1921-1946).

${ }^{6}$ John Settle Addison nasceu em São Francisco do Sul, Santa Catarina, em 4 de novembro de 1915. Engenheiro-civil formado pela Escola Politécnica de São Paulo em 1939, permaneceu como professor das aulas de Desenho

Topográfico e Cartográfico até sua aposentadoria, em 1976 (Escola Politécnica, 1945-1976).
} 
D'Elboux, J. R. | O Ensino do desenho de letras para engenheiros-arquitetos na Escola Politécnica de São Paulo: uma abordagem convencional

professor adjunto da disciplina desde 1945. Addison, como seus antecessores, manteve a cópia de uma prancha como trabalho inicial, a qual passou a ser denominada de "Letreiros, Escalas Gráficas e Símbolos Convencionais", reproduzida na Figura 4 (Addison, 1947).

Figura 1: Prancha com exercícios de desenho de letras feita por aluno do Professor Victor Dubugras em 1915 (Neves, 1943: 65. Usado com a permissão da Escola Politécnica da USP)
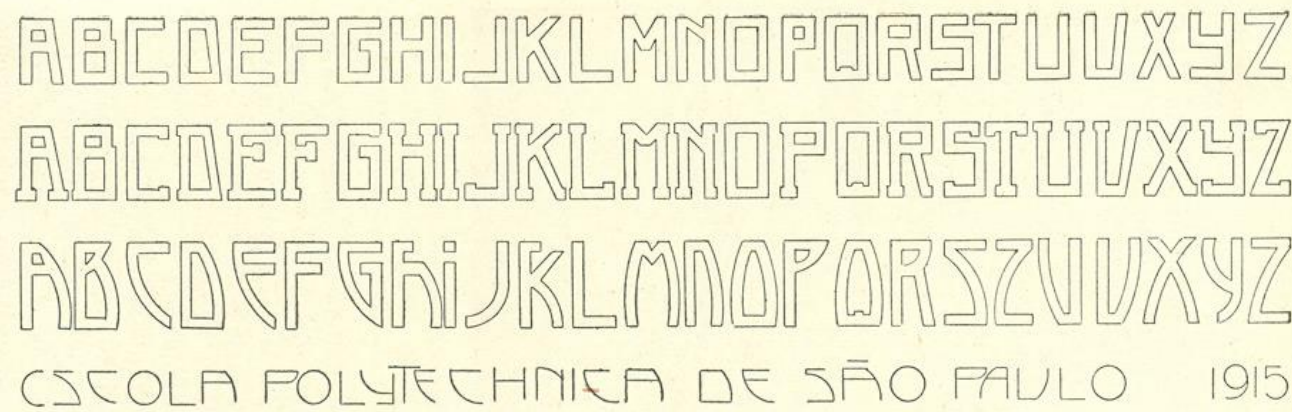

CURSO PRELIMINAR - DESEMHO GEOMETRICO DE TOPOGRAPHIA- MECMRIICA- CARPINTARIA

1234567890 FRCHITECTURA- COMSTRUCCÃO DESEMHADOS EM TRACOS MEDAMAMENTE OROSSOS

EGUAES, UMIFORMES COM MAMKIM RERAIXADO METADE DE AGUA SECTAO LOTGTI]
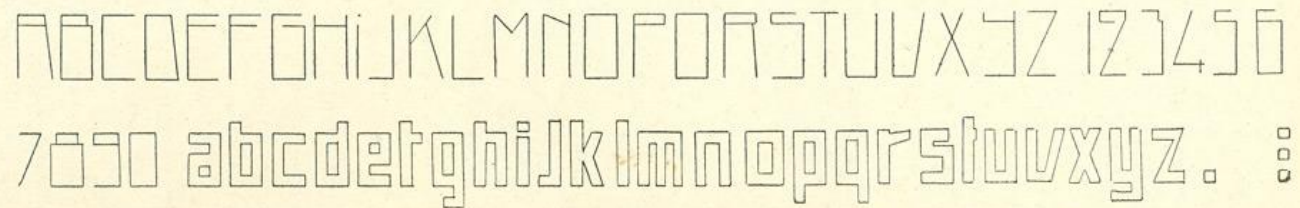

Desenho de aluno da Esc. Pol. de S. Paulo. Orientação do Prof. Dubugras (1915). 
D'Elboux, J. R. | O Ensino do desenho de letras para engenheiros-arquitetos na Escola Politécnica de São Paulo: uma abordagem convencional

Figura 2: Prancha com modelos de letras, letreiros, escalas gráficas e sinais convencionais de autoria do professor Jorge Krichbaum, 1914 (Usado com a permissão da Escola Politécnica da USP)

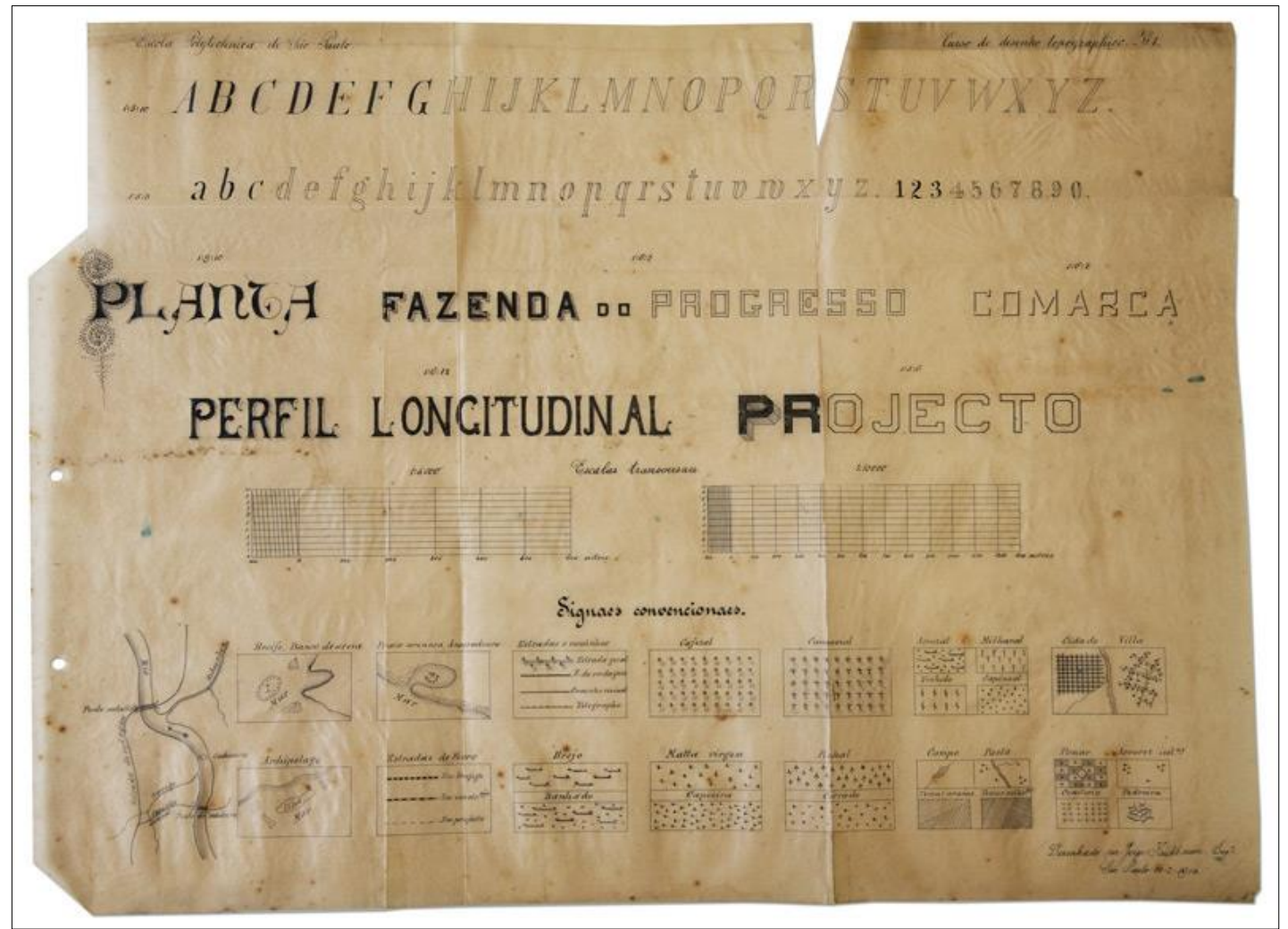

Anais do 9o Congresso Internacional de Design da Informação | CIDI 2019 
D'Elboux, J. R. | O Ensino do desenho de letras para engenheiros-arquitetos na Escola Politécnica de São Paulo: uma abordagem convencional

Figura 3: Prancha com modelos de letras, letreiros, escalas gráficas e sinais convencionais de autoria do professor Francisco Sales Vicente de Azevedo, 1922 (Usado com a permissão da Escola Politécnica da USP)

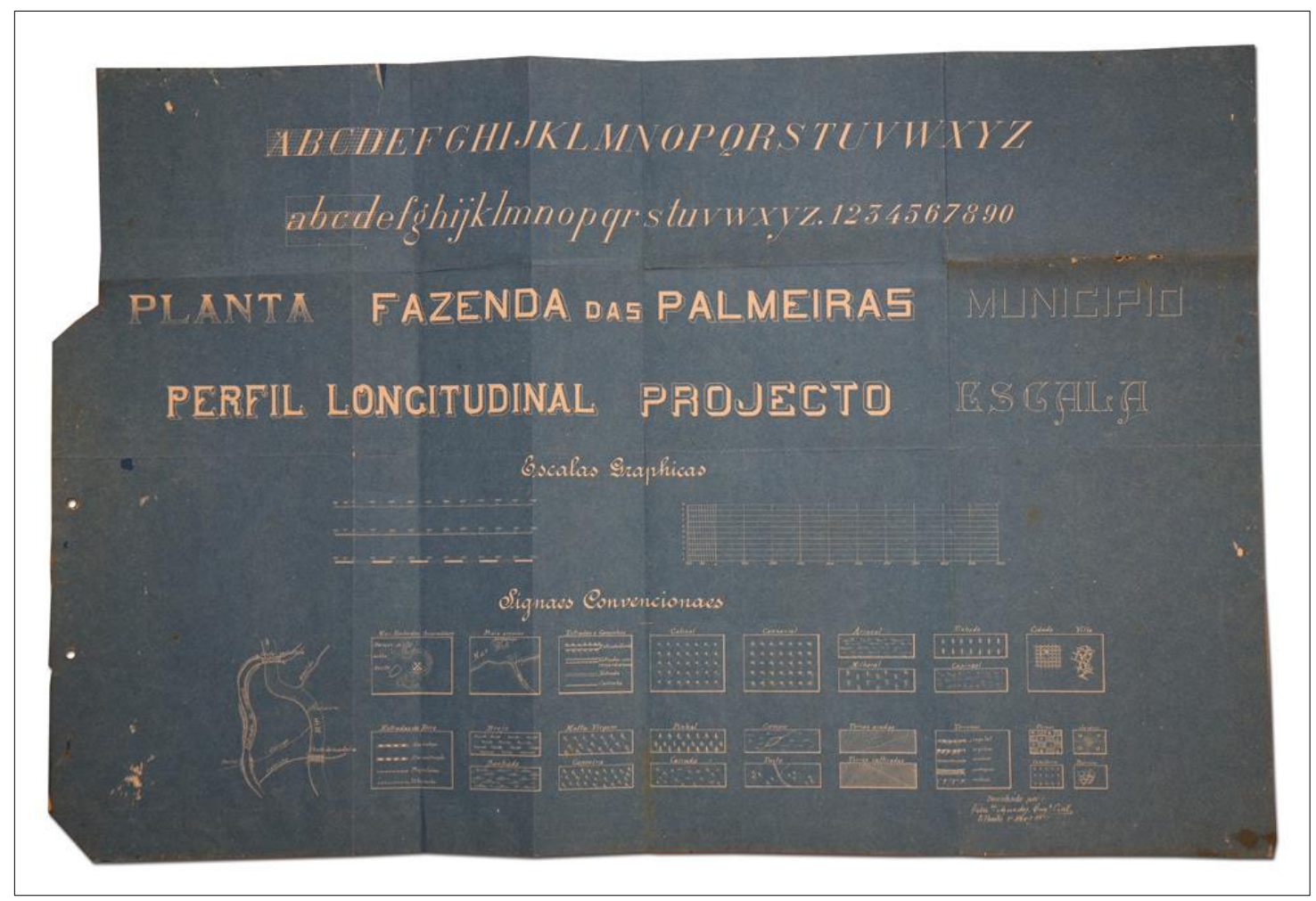

Figura 4: Prancha com modelos de letras, letreiros, escalas gráficas e sinais convencionais de autoria do professor John Settle Addison, 1948 (Addison, 1948. Usado com a permissão da Escola Politécnica da USP)

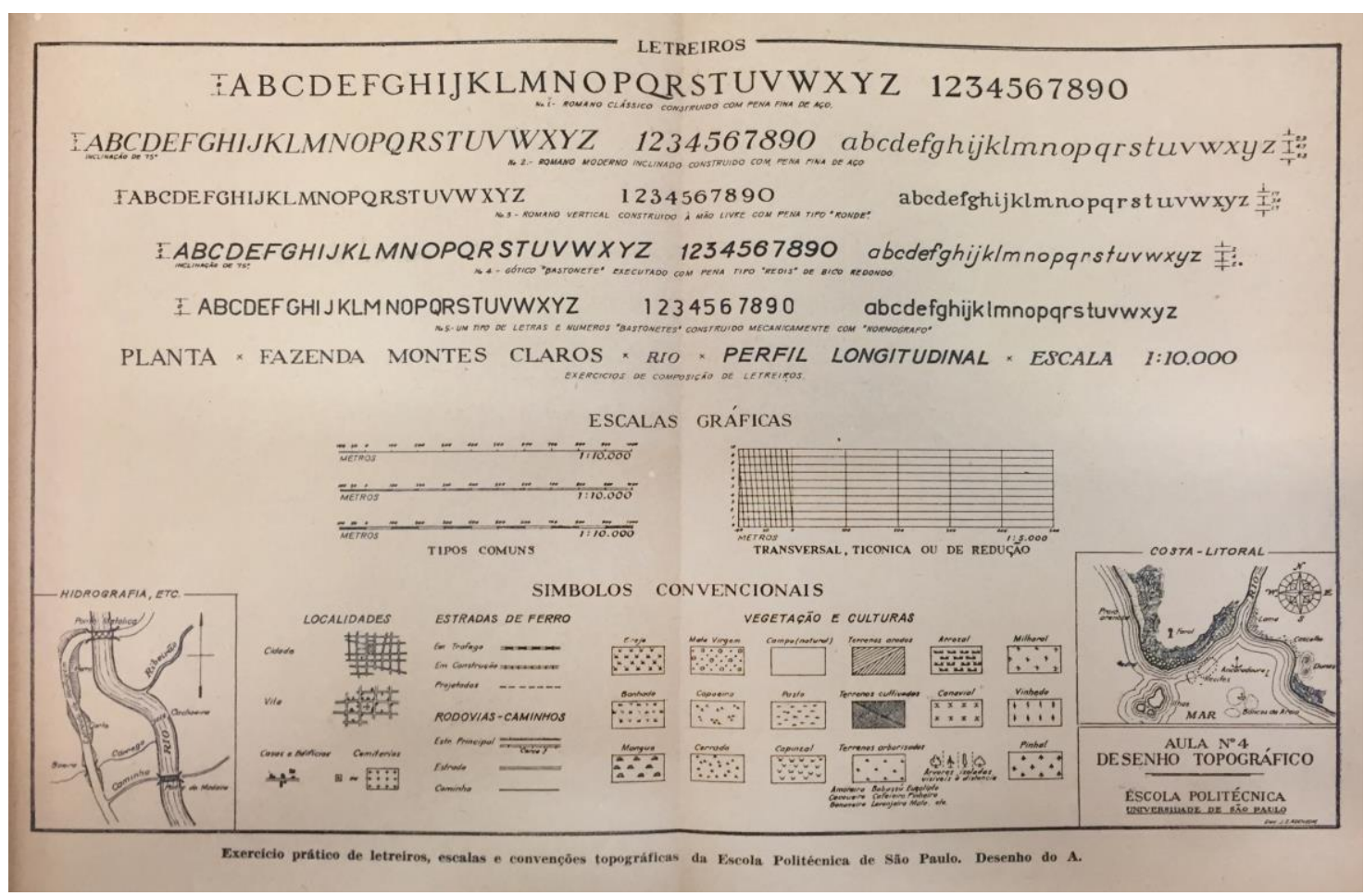

Anais do 9 Congresso Internacional de Design da Informação | CIDI 2019 
O professor Addison deixou documentos manuscritos onde explica detalhadamente 0 processo para a execução desse exercício, e também, um tipo de apostila onde aborda o ato de desenhar letras e letreiros, transmitindo regras de proporções, ângulos de inclinação, tipos de penas mais indicadas para cada tipo de letreiro. Sua apostila era ainda acompanhada por diferentes espécimes de alfabetos de referência. Esse material encontra-se reproduzido e transcrito nos anexos $\mathrm{A}$ e $\mathrm{B}$ da tese de doutoramento referida na introdução deste artigo (D'Elboux, 2018).

As pranchas de Krichbaum (Fig. 1), Azevedo (Fig. 2) e Addison (Fig. 3) são estruturalmente muito semelhantes, tendo a parte superior reservada para modelos de alfabetos completos; a intermediária, ocupada com exemplos de composição de letreiros em diferentes estilos; e, a inferior, apresentando as escalas gráficas e os sinais convencionais utilizados em desenhos topográficos e cartográficos.

A prancha utilizada pelo professor Victor Dubugras, cuja única referência disponível é uma reprodução do exercício executado por um aluno, foi uma exceção à essa divisão estrutural (Fig. 1). Convém lembrar que Victor Dubugras era arquiteto e, reconhecidamente, um dos expoentes em atividade nesse momento. Sua opção por ensinar alfabetos com características modernas, demonstra sua preferência pelo uso das letras e dos letreiros também como forma de expressão artística.

Os professores Jorge Krichbaum, Francisco de Sales Vicente de Azevedo e John Settle Addison, eram engenheiros, sendo os dois últimos, formados engenheiros-civis pela Escola Politécnica de São Paulo. Aparentemente, tentaram transmitir o conteúdo dessa aula de maneira similar à qual receberam. A manutenção da estrutura das pranchas é um indicativo disso.

O professor Krichbaum também demonstrou preferência pelas características artísticas das letras e dos letreiros, porém, suas opções são esteticamente mais conservadoras. Essa característica também é válida para os letreiros da prancha do professor Francisco de Sales Vicente de Azevedo, porém, em menor intensidade, já que o professor simplificou o desenho de alguns letreiros, abandonando a ornamentação excessiva das letras.

Nos alfabetos e letreiros do professor John Settle Addison, a opção pela clareza e legibilidade das informações é patente. O professor utilizou basicamente um modelo de alfabeto serifado e um grotesco de traçado simples, em versões vertical e inclinado. Addison também contemplou no exercício a utilização de normógrafo, instrumento surgido a partir de meados da década de 1920, que possibilitou a execução do letreiramento de maneira mecânica, trazendo maior padronização aos desenhos técnicos em geral.

\section{Desenho de letras em um contexto convencional}

Nos cursos de arquitetura oferecidos no âmbito das escolas de belas-artes, o desenho de letras costumava fazer parte das disciplinas ligadas ao desenho linear ou arquitetônico ${ }^{7}$. O desenho de letras, ensinado dentro do contexto do desenho topográfico e cartográfico, parece trazer ao assunto, um viés direcionado ao universo das convenções e normas gráficas.

É cedo para se tomar como referência as normas técnicas estabelecidas por instituições oficiais. Apesar da mais antiga, que deu origem à British Standards, ser de 1901, a norma que estabeleceu os padrões para o desenho técnico no Reino Unido, seria publicada somente em 1927. A alemã Deutsches Institut für Normung (DIN) é de 1917, a American National Standards Institute (ANSI), dos Estados Unidos, de 1918 e, a Association Française de Normalisation

\footnotetext{
${ }^{7}$ No Programa de 1934 do Liceu de Artes e Ofícios de São Paulo, o desenho de letras fazia parte do conteúdo de Desenho de Estampa, dentro da disciplina "Desenho Linear à Mão Livre", do Curso Geral de Artes (Severo, 1934: 113121). Na proposta de currículo mínimo para arquitetos, apresentada por Christiano Stockler das Neves, baseada no curso de arquitetura da Universidade da Pensilvânia, o desenho de letras fazia parte da disciplina "Architectural Design" (Neves, 1925: 7).
} 
(AFNOR), da França, 1926.

Por esse motivo, conforme mencionado na Introdução deste artigo, utilizamos a título de referência, o livro de C. W. Reinhardt intitulado "Lettering for Draftsmen, Engineers and Students: A practical system of freehand lettering for working drawings", editado pela D. Van Nostrand, de Nova lorque, e disponível na Biblioteca da Escola Politécnica da Universidade de São Paulo ${ }^{8}$.

Segundo Reinhardt, a intenção de seu tratado foi propor um sistema de letreiramento para uso específico em legendas e subtítulos de desenhos técnicos. Para tanto, segundo ele, as letras foram reduzidas às suas formas mais simples, possibilitando uma execução rápida, resultando em letreiros claros e adequados também à reprodução por meios fotográficos (Reinhardt, 1917, p. 37).

A obra conta ainda com uma seção de estampas que ilustram diferentes modelos de alfabetos serifados e grotescos para uso em títulos. E ainda, para uso geral, um modelo de caligrafia redonda ou ronde. Na edição de 1917, o autor dedica um capítulo à feitura de títulos, onde demonstra como a escolha de diferentes tamanhos e tipos de letra, podem auxiliar na hierarquização e visualização das informações, além de defender a diagramação centralizada das linhas como sendo a forma de diagramação ideal.

Uma possível influência do tratado de Reinhardt pode ser observada nas diferentes pranchas de letras e letreiros dos professores da Escola Politécnica de São Paulo, exceto na de Dubugras.

Na parte superior da prancha de Krichbaum, desenhada em 1914, vemos um alfabeto serifado e inclinado, em versões maiúscula e minúscula, e os algarismos correspondentes. Esse alfabeto encontra certa correspondência aos serifados apresentados por Reinhardt (1897, 1917) porém, difere destes no uso de letras inclinadas ao invés de itálicas como aparece no tratado. Krichbaum se utiliza ainda da caligrafia ronde para a rotulação da área de sua prancha que trata dos sinais convencionais (Fig. 2).

Nos letreiros compostos em diferentes estilos de letras, não existe nenhuma semelhante às apresentadas por Reinhardt $(1897,1917)$. Vemos letreiros compostos com maiúsculas lombardas 9 , um ' $P$ ' capitular ornamentado por iluminuras, letras geométricas de aspecto retangular e serifa do tipo egípcia, letras curvilíneas em estilo art nouveau e, uma série de exemplos de tratamentos ornamentais utilizando filetes, sombreados, hachuras, que passam uma sensação de volumetria e alto-relevo aos letreiros.

A prancha de Azevedo, de 1922 (Fig. 3) é bastante semelhante à de Krichbaum, porém o professor abandona o uso da capitular ornamentada e utiliza no letreiro "PLANTA", uma letra com serifa triangular, ornamentada com hachuras em seu interior. O desenho e acabamento desse letreiro, é muito semelhante ao encontrado na estampa no4 do livro de Reinhardt (1897). Azevedo também se utiliza da caligrafia ronde para indicar as áreas denominadas "Escalas Gráficas" e "Sinais Convencionais". No restante, Azevedo mantém os mesmos modelos de letras utilizados por Krichbaum em sua prancha: letras curvilíneas em estilo art nouveau, maiúsculas lombardas, letras geométricas de aspecto quadrado, com e sem a serifa egípcia e, um alfabeto serifado inclinado completo.

Na prancha utilizada pelo professor Addison em 1948, é possível observar que os tipos de letras utilizados são bem mais discretos do que os utilizados nas pranchas de seus predecessores. São cinco alfabetos completos, com maiúsculas, minúsculas e algarismos. Três deles serifados - Romano Clássico e Romano Moderno Inclinado construídos com pena fina de aço; Romano Vertical construído à mão livre com pena tipo ronde - e dois não serifados - que o professor chama de Gótico "Bastonete", para ser executado com pena tipo "Redis" de bico redondo e, um tipo de letras e números "bastonetes" construído mecanicamente com

\footnotetext{
${ }^{8}$ A Biblioteca Central da Escola Politécnica da USP possui em seu acervo, um exemplar da 14aㅡ edição, de 1917. Também foi consultada cópia digital da 3aㅡ edição, de 1897, disponível em http://archive.org

${ }^{9}$ Como referência para nomenclatura de caligrafias históricas foi utilizado Harris, 2009.
} 
"normógrafo" - conforme indicado por Addison em legendas abaixo de cada um desses alfabetos.

Esses desenhos de letra, estão bem mais próximos aos propostos por Reinhardt (1897, 1917) para uso em subtítulos e legendas e, também, aos modelos que passaram a ser recomendados pela Associação Brasileira de Normas Técnicas (ABNT), que foi instituida oficialmente em $1940^{10}$.

A norma brasileira referente à execução de desenhos técnicos, a NB-8R é do ano de $1943^{11}$. Em seu capítulo V, intitulado "Letras e Anotações", a norma estabelece o uso de letras verticais ou inclinadas entre $60^{\circ}$ e $75^{\circ}$, com a possibilidade de combinação de maiúsculas e minúsculas. E, ainda, que os tipos de letras deveriam ser legíveis e, preferencialmente, correspondentes aos modelos apresentados pela norma, com tamanhos proporcionais ao desenho (ABNT, 1947, p. 3-4).

O estabelecimento dessa norma aconteceu dois anos antes de Addison se tornar professor na Escola Politécnica. O conteúdo de sua prancha portanto, parece alinhado às recomendações da NB-8R em relação aos letreiros, sendo os modelo recomendados pela norma, bastante similares aos alfabetos do tipo "bastonete" 4 e 5 existentes em sua prancha.

Em tese para o concurso de professor para a aula de "Desenho Topográfico e Cartográfico", apresentada à Escola Politécnica em 1948, Addison critica as limitações impostas pela ABNT para a execução dos desenhos técnicos, pois, segundo o professor, estas poderiam provocar uma estagnação no desenvolvimento do desenho técnico, já que este, também seria expressão da época em que é executado. O professor, a título de exemplo, cita as transformações causadas nos desenhos com o surgimento do normógrafo (Addison, 1948, p. 12).

Apesar desse fato, o professor se mostra extremamente minucioso no estabelecimento de regras para o desenho das letras, principalmente sua inclinação e proporções. Em sua apostila de 1945, ele chegou a mencionar a norma DIN 16, que estabeleceria a espessura das letras em $1 / 10$ da altura da letra "a" minúscula. Entretanto, na opinião do professor, o ideal nessa relação seria algo em torno de 1/6 ou 1/7 (Addison, 1945).

\section{Hierarquização de informações}

Observando os letreiros que compõem as pranchas de exercícios propostas pelos três engenheiros, é possível notar uma certa hierarquia condicionada à natureza da informação representada. Fato que não é observado na prancha proposta pelo também professor da disciplina de "Desenho Topográfico e Cartográfico", o arquiteto Victor Dubugras. Na Figura 5, vemos em detalhe os letreiros das pranchas dos três professores.

\footnotetext{
${ }^{10}$ Os estudos sobre o concreto armado realizados a partir do início do século passado no Gabinete de Resistência de Materiais da Escola Politécnica de São Paulo dariam origem futuramente ao surgimento da ABNT (ABNT, 2011: 26-28).

${ }^{11}$ As convenções cartográficas foram normatizadas a partir de 1956, pela P-NB-63R (ABNT, 1981: 331).
} 
Figura 5: Detalhe da área de letreiros das pranchas. Krichbaum (superior), Azevedo (central) e Addison (inferior) (Usado com a permissão da Escola Politécnica da USP)
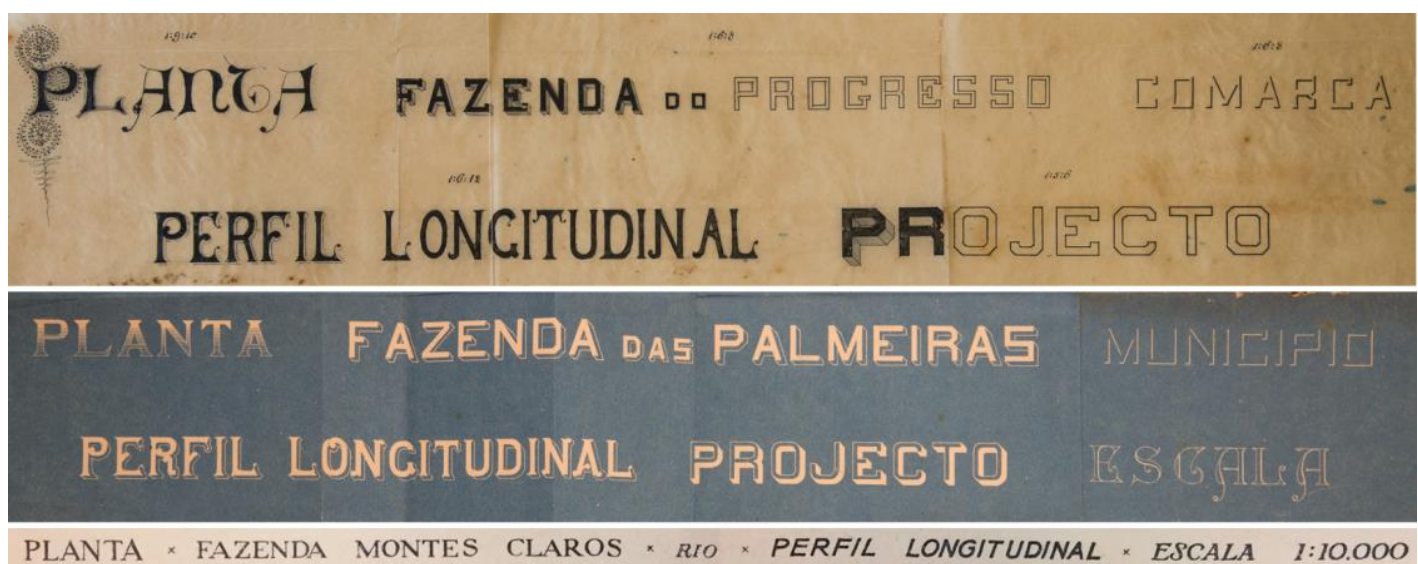

É possível observar que no nível mais alto da hierarquia, estão os letreiros que fazem referência ao próprio desenho ou projeto, como "PLANTA", "PERFIL LONGITUDINAL", "PROJETO" e "ESCALA". Nas pranchas de Krichbaum e Azevedo, essa hierarquização pode ser entendida pelo nível de ornamentação do alfabeto selecionado para o letreiro e, também, pelo tamanho relativo de suas letras. Por exemplo, a palavra "PLANTA" é a mais ornamentada. Krichbaum escolheu para ela uma letra lombarda e, ainda fez uso de uma capitular ornamentada. Azevedo, para a mesma palavra, preferiu uma letra serifada e ornamentada com hachuras. Addison utilizou uma romana clássica, diferenciada pelo tamanho das letras, maiores do que as dos demais letreiros.

A legenda "PERFIL LONGITUDINAL" aparece com o mesmo tipo de letra curvilínea nas pranchas de Krichbaum e Azevedo, em estilo art nouveau e ornamentada por filetes. Já Addison, utiliza para essa palavra, uma letra do tipo bastão inclinada, com hastes de espessura mais grossas em relação aos demais letreiros de sua prancha, garantindo à ela, certo destaque.

A palavra "PROJETO", também tem desenho semelhante nas pranchas de Krichbaum e Azevedo, em letras tipo 'bloco', de aspecto quadrado com efeitos ornamentais de volumetria e sombra. Essa palavra não aparece na prancha de Addison. A palavra "ESCALA", aparece na prancha de Azevedo em lombardas desenhadas somente pelo contorno e, na prancha de Addison, em uma serifada inclinada, não constando da prancha de Krichbaum.

No nível intermediário, encontramos os nomes de propriedades como "FAZENDA DO PROGRESSO" na prancha de Krichbaum e "FAZENDA DAS PALMEIRAS", na de Azevedo, ambas, em letras do tipo 'bloco'. Na prancha de Addison, aparece "FAZENDA MONTES CLAROS", em letras romanas com tamanho um pouco menor em relação às palavras descritas nos parágrafos anteriores.

No último nível, estariam as divisões administrativas e acidentes geográficos. "COMARCA" na prancha de Krichbaum, "MUNICÍPIO" na de Azevedo, ambas em letras do tipo 'bloco' de aspecto quadrado, que foram desenhadas apenas por alguns de seus contornos, o que dá à esses letreiros dando um aspecto de sutil relevo. Na prancha de Addison, temos a palavra "RIO" desenhada somente pelos contornos, com letras serifadas inclinadas, de menor tamanho entre os letreiros existentes.

Esse tipo de abordagem hierárquica por natureza de informação, parece se repetir em uma planta que foi desenhada por Jorge Krichbaum, no ano de 1892, anterior portanto, à sua entrada na Escola Politécnica de São Paulo. Um detalhe da área do título desse desenho, foi reproduzido na Figura 6. Nele, Krichbaum se utiliza de diferentes tipos de letras para obter diferenciação em diferentes trechos que compõe o título do desenho: a lombarda com capitular ornamentada para a palavra "PLANTA", a geométrica de aspecto retangular e serifa egípcia 
para "DOS TERRENOS", e uma letra gótica do tipo textura, para o nome do proprietário "José Garnier". Ele ainda utiliza um alfabeto serifado itálico para "Situados no Marco de Meia-Legua" e, uma caligrafia do tipo copperplate para a indicação da escala.

Figura 6: Detalhe de planta desenhada por Jorge Krichbaum em 1892 (Usado com a permissão do Museu Paulista da Universidade de São Paulo. Acervo MPUSP. Reprodução fotográfica de Hélio Nobre/José Rosael)

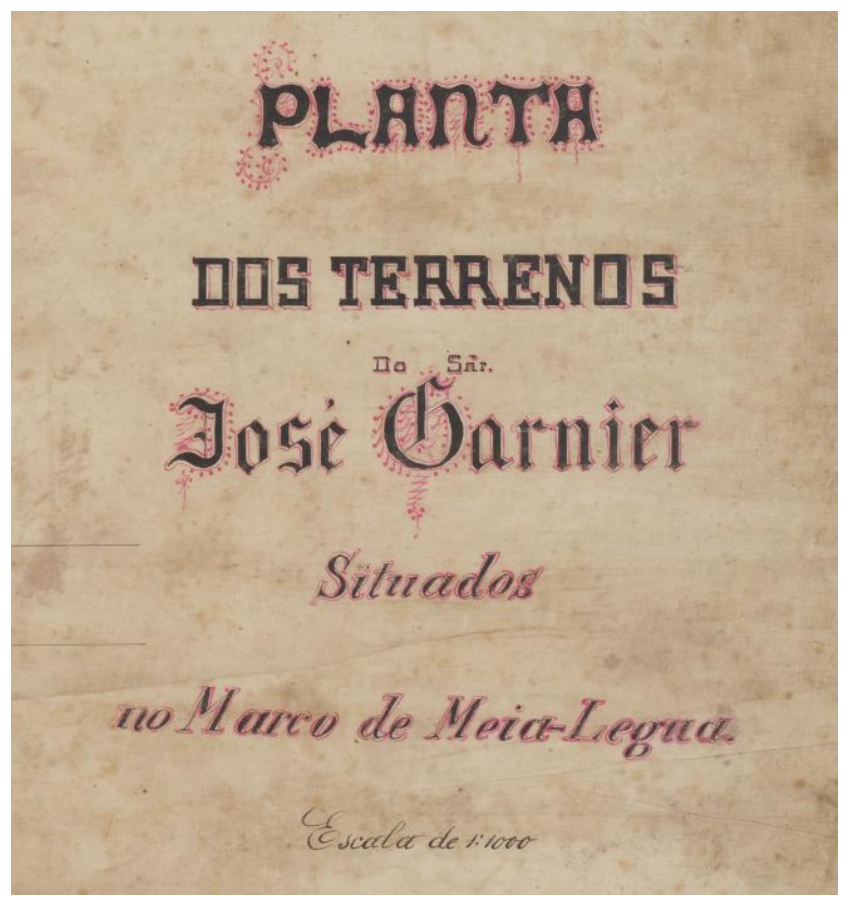

\section{Considerações Finais}

O ensino do desenho de letras no curso de engenheiro-arquiteto da Escola Politécnica de São Paulo, fazia parte do conteúdo da disciplina "Desenho Topográfico e Cartográfico". Como principal trabalho, os professores sugeriam um exercício de cópia de uma prancha com modelos de alfabetos e letreiros, junto com sinais e convenções utilizados no desenho de mapas e plantas topográficas. Esse tipo de abordagem metodológica manteve-se inalterado durante todo o período estudado, ficando as principais modificações, restritas aos alfabetos, tipos de letras e letreiros que faziam parte desse exercício.

Apesar de já existirem naquele momento esforços para o uso de modelos de letras mais simples e racionais para a utilização em desenhos técnicos, conforme visto em Reinhardt (1897, 1917), Dubugras, Krichbaum e Azevedo, preferiram transmitir aos alunos, tipos de letras com características artísticas, fossem estes modelos contemporâneos, como no caso de Dubugras ou conservadores, no caso de Krichbaum e Azevedo.

Na prancha de Victor Dubugras, único arquiteto que lecionou a aula de "Desenho Topográfico e Cartográfico", os alfabetos escolhidos mais pareciam versões diferentes de uma mesma família de letras em estilo Sezession.

Por estar contido no conteúdo das aulas de desenho topográfico e cartográfico - provável adequação pelo fato desta ser uma disciplina básica e comum a diferentes cursos de engenharia da Escola Politécnica de São Paulo - o desenho de letras ganhou um viés convencional na aplicação dos modelos de alfabetos e letreiros, principalmente na visão dos professores engenheiros, Krichbaum, Azevedo e Addison, onde a utilização de níveis hierárquicos foram atrelados às diferentes naturezas das informações textuais contidas nas pranchas. 
Esse fato aconteceu independentemente das alterações nos modelos das letras com o decorrer dos anos, pois foi observado desde os tipos de letras históricos e ornamentais ensinados pelos professores Krichbaum e Azevedo, até aqueles que passaram a apresentar desenho cada vez mais simplificado e mecânico, ensinados pelo professor Addison.

\section{Referências}

Addison, J. S. (1945). Apostila datilografada. São Paulo: EPUSP (1947). Manuscrito "Aula no 4 - Desenho Topográfico". São Paulo: EPUSP (1948). Desenho Cartográfico. Tese apresentada para concurso de professor. São Paulo: EPUSP

ANSI American National Standards Institute. In: ANSI: Celebrating 100 Years 1918- 2018. <https://www.ansi.org/about_ansi/introduction/history?menuid=1>, 21/06/2019

ABNT Associação Brasileira de Normas Técnicas (1947). Normas Recomendadas. Rio de Janeiro: ABNT.

(1981). Normas para Desenho Técnico [Org.] Paulo de Barros Ferlini. Porto Alegre: Editora Globo.

(2011). História da normalização brasileira. Rio de Janeiro: ABNT.

D'Alessandro. A. (1943-1944). A Escola Politécnica de São Paulo: histórias da sua história. São Paulo: Revista dos Tribunais.

D'Elboux, J. R. (2018) Letras e letreiros: manifestações do Art Déco em projetos arquitetônicos paulistanos (1925-1955). Tese de Doutorado. São Paulo: FAUUSP

DIN Deutsches Institut für Normung. In: 100 years of DIN.

<https://www.din.de/en/din-and-our-partners/100/timeline>, 21/06/2019.

ESCOLA POLITÉCNICA DE SÃO PAULO (1900). Anuário Politécnico. São Paulo: EPUSP. (1901). Anuário Politécnico. São Paulo: EPUSP.

(1932). Anuário Politécnico. São Paulo: EPUSP.

(1921-1946). Ficha de registro de Francisco de Sales Vicente de Azevedo. São Paulo: EPUSP.

(1945-1976). Ficha de registro de John Settle Addison. São Paulo: EPUSP.

Ficher, S. (2005). Os Arquitetos da Poli. São Paulo: EDUSP.

Harris, D. (2009). A arte da caligrafia: um guia prático, histórico e técnico. São Paulo: Ambientes \& Costumes.

Krichbaum, J. (1912). Programa da aula de "Desenho Topográfico" do 1ํAno do Curso Geral. São Paulo: EPUSP.

Martinez, I. M. Standardization in France. In: Government Publishing Office [US].

<https://www.govinfo.gov/content/pkg/GOVPUB-C13-

2063e08eca6121b8264d9e26177243b1/pdf/GOVPUB-C13-

2063e08eca6121b8264d9e26177243b1.pdf >, 21/06/2019.

Munford, P. (2009). Technical drawing standards: a brief history (BS 308 and all that). In: cadsetterout.com <https://cadsetterout.com/drawing-standards/bs-308-and-all-that>, 24/06/2019.

Neves, C. S. (1927). Plan of minimum studies for architects in the universities of America, in order that the diplomas given may ensure professional rights in all the countries of the continent. São Paulo: Seção de Obras do O Estado de São Paulo. 
D'Elboux, J. R. | O Ensino do desenho de letras para engenheiros-arquitetos na Escola Politécnica de São Paulo: uma abordagem convencional

Neves, J. M. S. (1943). Desenho Arquitetônico. Tese apresentada para concurso de professor. São Paulo: EPUSP.

Reinhardt, C. W. (1897). Lettering for Draftsmen, Engineers and Students: A practical system of freehand lettering for working drawings. New York: D. Van Nostrand.

(1917). Lettering for Draftsmen, Engineers and Students: A practical system of freehand lettering for working drawings. New York: D. Van Nostrand.

REVISTA POLITÉCNICA (1922). Jorge Krichbaum. Revista Politécnica, n. 6: pp. 497-498.

Ssantos, M. C. L. (1985). Escola Politécnica da Universidade de São Paulo: 1894-1984. São Paulo: RUSP.

Severo, R. (1934). O Liceu de Artes e Ofícios de São Paulo: histórico, estatutos, regulamentos, programas, diplomas. São Paulo: Liceu de Artes e Ofícios de São Paulo.

\section{Sobre o autor}

José Roberto D'Elboux, ScD, FAUUSP, Brasil, <delboux@usp.br> 